\title{
A PRECEDE-PROCEED MODEL ON THE DETERMINANTS OF ADHERENCETO HIV TREATMENT: A PATH ANALYSIS EVIDENCE FROM INDONESIA
}

\author{
DYAH AYU AGUSTIN ${ }^{1,2 *}$, BHISMA MURTI ${ }^{1}$ \\ ${ }^{1}$ Department of Health Promotion and Behavior, Master's Program in Public Health, Universitas Sebelas Maret, Indonesia. ${ }^{2}$ School of \\ Health Sciences Kendedes Malang, Indonesia. Email: ayuagustin20@gmail.com
}

Received: 11 June 2018, Revised and Accepted: 06 July 2018

\section{ABSTRACT}

Objective: Adherence is increasingly recognized as an important determinant of successful HIV treatment (also called antiretroviral therapy [ART]). Poor adherence may cause ART failure and increase the risk of drug resistance. No prior studies have explained the reasons for poor adherence to ART among HIV-infected patients in Indonesia. This study aimed to investigate the determinants of adherence to ART among HIV-infected patients using precede-proceed model and path analysis.

Methods: This was an analytic observational study with a cross-sectional design. The study was carried out at Dr. Moewardi Hospital, Surakarta, Central Java, Indonesia, from January to March 2018. A total of 284 HIV-infected patients visiting Dr. Moewardi Hospital for ART was selected for this study by simple random sampling. The dependent variable was adherence to ART. The independent variables included adverse effect, patient knowledge, income, depression, trust in provider, ART supply by the government, family support, stigma, discrimination, distance, and travel expenditure. The data were collected by pre-tested questionnaire and analyzed by path analysis.

Results: Adherence to ART was directly and positively affected by government supply of ART (b=2.10; 95\% confidence interval (CI)=0.85-3.36; $\mathrm{p}<0.001)$, patient knowledge $(\mathrm{b}=1.70 ; 95 \% \mathrm{CI}=0.43-2.95 ; \mathrm{p}=0.008)$, and trust in provider $(\mathrm{b}=2.14 ; 95 \% \mathrm{CI}=-0.58-4.87 ; \mathrm{p}=0.123)$. Adherence was directly but negatively affected by adverse effect $(b=-4.17 ; 95 \% \mathrm{CI}=-6.87--1.47 ; \mathrm{p}=0.879)$, depression $(\mathrm{b}=-2.38 ; 95 \% \mathrm{CI}=-4.15--0.62 ; \mathrm{p}=0.002)$, stigma ( $b=-4.10 ; 95 \% \mathrm{CI}=-6.49--1.71 ; \mathrm{p}=0.008)$, and travel expenditure $(\mathrm{b}=-1.52 ; 95 \% \mathrm{CI}=-2.68$ to $-0.36 ; \mathrm{p}<0.001)$.

Conclusion: Adherence is indirectly and positively affected by patient satisfaction, income, family support, but indirectly and negatively affected by discrimination and distance. This study concludes that government supply of ART, patient knowledge, and trust in provider, positively affect adherence to ART. Adverse effect, depression, stigma, and travel expenditure negatively affect adherence.

Keywords: Antiretrovirus therapy, Adherence, Precede-proceed model, Path analysis

(C) 2018 The Authors. Published by Innovare Academic Sciences Pvt Ltd. This is an open access article under the CC BY license (http://creativecommons. org/licenses/by/4. 0/) DOI: http://dx.doi.org/10.22159/ajpcr.2018.v11i11.27861

\section{INTRODUCTION}

Adherence is increasingly recognized as an important determinant of successful antiretroviral therapy (ART) even if it is provided free of charge [1]. Adherence refers to sticking firmly to an HIV regimen everyday and exactly as prescribed. Treatment adherence includes initiating care with an HIV provider (linkage to care), regularly attending appointments (retention in care), and adherence to AR [2-5]. HIV regimens can include numerous pills with frequent dosing and various, sometimes conflicting, food requirements [6].

Poor adherence can lead to ART failure. Poor adherence to an HIV regimen allows HIV to destroy the immune system and a damaged immune system makes it hard for the body to fight off infections and certain cancers. As studies have shown, poor CD4 gain in HIV-infected patient follows poor adherence [7]

Moreover, poor adherence increases the risk of drug resistance [8]. Drug resistance refers to the ability of disease-causing germs, such as bacteria and viruses, to continue multiplying despite the presence of drugs that usually kill them. Drug resistance can develop as HIV multiplies in the body. When HIV multiplies, the virus sometimes mutates (changes form) and makes genetic structural variations of itself. Failure to take the prescribed doses of antiretroviral drugs leads to ongoing viral replication in the presence of drug and the selection of drug-resistant HIV [9]

Taking HIV medicines everyday prevents HIV from multiplying, which reduces the risk that HIV will mutate and produce drug-resistant HIV.
Otherwise, skipping HIV medicines allows HIV to multiply, which increases the risk of drug-resistant HIV developing. However, in a developed country such as the US with relatively better health-care system than most developing countries, after receiving an HIV diagnosis, only about $75 \%$ of individuals are linked to care within 30 days. Only $57 \%$ of persons who receive an HIV diagnosis are retained in HIV care. Moreover, it is estimated that only approximately 55\% of persons with diagnosed HIV are virally suppressed because of poor linkage to care and retention in care [10]. On top of that, as is the case in other serious illness, medication non-adherence places a significant cost burden on health-care systems [11]

Non-adherence, however, is a complicated phenomenon and decades of research have attempted to establish its clear connection with variables that can be altered and improved in the course of HIV/AIDS clinical care. A commonly cited cause of poor adherence to highly active antiretroviral therapy (HAART) is adverse drug reactions [5]. Adverse effects from some HIV medicines, such as nausea or diarrhea, can make it hard to follow an HIV regimen. Adverse events may lead to discontinuation of therapy, dose interruption, and significant reductions in quality of life [12].

The precede-proceed model is a comprehensive structure for assessing health needs for designing, implementing, and evaluating health promotion and other public health programs to meet those needs. This model was first developed and introduced in the 1970s by Lawrence et al. [13]. It is an ecological approach to health promotion, which embodies two key aspects of intervention: (a) planning (precede component) and 
(b) evaluation (proceed component). The precede component includes an ecological assessment that analyzes the predisposing, reinforcing, and enabling factors that determine the behavior in question (i.e. adherence to HIV treatment in the current study) [14].

To the best of the authors knowledge, there were no prior studies that explained the reasons for poor adherence to HIV treatment among HIVinfected patients in Indonesia using precede-proceed model as the conceptual framework and path analysis as the data analytic approach. Therefore, the current study aimed to investigate the determinants of adherence to HIV regimen among HIV-infected patients in Indonesia using the precede-proceed model and path analysis approach. Information from the current study can be used to develop a system of care and support that can improve adherence to antiretroviral therapy and the well-being of HIV-infected patients.

\section{METHODS}

\section{Study design}

This study was analytic-observational with a cross-sectional design. It was conducted at Dr. Moewardi Hospital, Surakarta, Central Java, Indonesia, from February to March 2018.

\section{Population and sample}

A total of 284 study subjects was selected for this study by exhaustive sampling from all HIV-infected patients who visited Dr. Moewardi hospital for ART from February to March 2018

\section{Study variables}

The dependent variable was adherence to ART (coded 0 - poor; 1 - good). The independent variables included the biological and psychosocial variables, which fell into three categories: predisposing, enabling, and reinforcing factors of the precede-proceed model.

The predisposing factors included adverse effect (coded 0 - absent; 1 - present), patient's knowledge (coded 0 - low; 1 - high), income (coded $0 \leq \operatorname{Rp} 1,500,000 ; 1 \geq \operatorname{Rp} 1,500,000$ per month), satisfaction (coded 0 - low; 1 - high), depression (coded 0 - low; 1 - high), and trust in provider (coded 0 - low; 1 - high). The enabling factors included ART supply by the government (coded 0 - late; 1 - timely).

The reinforcing factors included family support (coded 0 - weak; 1 - strong), stigma (coded 0 - weak; 1 - strong), discrimination (coded 0 - non-existent; 1 - existent), distance to ART centers (coded $0 \leq 20 \mathrm{~km}$; $1 \geq 20 \mathrm{~km}$ ), and travel expenditure (coded 0 - low; 1 - high).

Adherence to ART was defined as the patient's behavior on the number of pills taken, timeliness of visit to the ART center, accuracy of dose, and percentage of the total amount of prescribed medication. This variable was measured by self-reported questionnaire coupled with data from the secondary record in the voluntary counseling and testing clinic at Dr. Moewardi Hospital.

Stigma was defined as a mark of disgrace that a society gave to HIVinfected patients. Discrimination was defined as the unjust or prejudicial treatment of the patients, on the grounds of HIV infection status, which might come from the society, health workers, and family. Depression was defined as a mood disorder characterized by low mood, a feeling of sadness, and a general loss of interest in things. Family support was defined as the study subject's perception of the positive support provided by the family for those activities pertinent to HIV treatment, which included financial, instrumental, emotional, and informational support. All of these key variables were measured by a pre-tested questionnaire. Depression was measured by pre-tested instrument called "Mini International Neuropsychiatric Interview" [15].

\section{Data analysis}

The current study employed path analysis for data analysis. Path analysis is the statistical technique that allows an examination of causal relationships between one or more independent variables, either continuous or categorical, and one or more dependent variables, either continuous or categorical. It is a second-generation multivariate method (the first generation being multiple regression) based on a linear equation system and was first developed by Sewall Wright in the 1930s [16]. The path analysis was run using Stata 13 [17].

\section{Ethical clearance}

Research ethics approval was granted by the Research Ethics Committee at Dr. Moewardi Hospital, Surakarta, Central Java, Indonesia. The research ethical approval was stated in the Letter of Ethical Approval Number 31/I/HREC/2018.

In data collection process, patients 18 or more years of age were asked to give informed consent, so that the study subjects were voluntarily participating in the research with full knowledge of relevant risks and benefits. The other key ethical principles that this study followed included: (1) Respect for participants, (2) Informed consent, (3) Voluntary participation and no coercion, (4) Right to withdraw, (5) No harm to participants, (6) Avoidance of undue intrusion, (7) No use of deception, (8) Preservation of anonymity, (9) Confidentiality of personal matters, and (10) Data protection.

\section{RESULTS}

\section{Sample characteristics}

Table 1 describes sample characteristics of this study. The majority of study subjects were male aged 35 years or over with senior high school level of education. Two-third of the sample were heterosexual and about a third were homosexual.

One of the encouraging findings from this study is that about four-fifth of the sampled HIV-infected patients received strong support from their families. "Only" about $10 \%$ of the sample got stigma or discrimination from either the society, health worker, or family. Another good finding is that about $90 \%$ of the sample had strong trust in health-care providers. As many as $13.4 \%$ of the sampled HIV-infected patients experienced high depression. The majority (78.5\%) of the HIV-infected patients adhered to ART.

\section{Path diagram}

Fig. 1 depicts the final path diagram on the determinants of adherence to HIV/AIDS treatment, based on precede-proceed model. It shows that government supply of ART, patient knowledge, trust in provider, adverse effect, depression, stigma, and travel expenditure have direct effects on adherence to HIV treatment. Patient satisfaction, income, family support, discrimination, and distance to ART centers have indirect effects on HIV treatment.

\section{Path analysis}

Table 2 showed the effect estimates on the determinants of adherence to HIV treatment, based on precede-proceed model, using path analysis. As customary for reporting the path analysis output, the top-left panel of the table lists the independent variables that have direct effects on the dependent variable (i.e., adherence to HIV treatment). The bottomleft panel of the table lists the independent variables that have direct effects on the dependent variable. The sign of the path coefficient indicates the direction of the effect, either increasing (+) or decreasing (-) with 0 indicating no effect (null hypothesis).

Because the dependent variable and all the independent variables were measured in dichotomous scale (dummy coded), basically the magnitude of path coefficient indicates the effect on the log odd of the dependent variable for a change (departure) from the reference category of an independent variable to the other category of the same independent variable, while taking account of the effects of all other variables in the path model.

All of the hypotheses on the relationships of variables in question were supported by data analysis. As hypothesized, government supply of ART (b=2.10; 95\% confidence interval $(C I)=0.85-3.36 ; p<0.001)$ 
Table 1: Sample characteristics

\begin{tabular}{|c|c|c|}
\hline No & Characteristics & n (\%) \\
\hline \multirow[t]{4}{*}{1} & Age (years) & \\
\hline & $<20$ & $3(1.1)$ \\
\hline & $20-35$ & $113(39.8)$ \\
\hline & $>35$ & $168(59.2)$ \\
\hline \multirow[t]{3}{*}{2} & Gender & \\
\hline & Female & $97(34.2)$ \\
\hline & Male & $187(65.8)$ \\
\hline \multirow[t]{3}{*}{3} & Education & \\
\hline & $<$ Senior high school & $87(30.6)$ \\
\hline & $\geq$ Senior high school & $197(69.4)$ \\
\hline \multirow[t]{3}{*}{4} & Income & \\
\hline & $\geq$ Regional minimum wage & $127(44.7)$ \\
\hline & $<$ Regional minimum wage & $157(55.3)$ \\
\hline \multirow[t]{5}{*}{5} & Risk factor & \\
\hline & Heterosexual & $193(68.0)$ \\
\hline & Homosexual & $81(28.5)$ \\
\hline & IDU & $8(2.8)$ \\
\hline & Perinatal & $2(0.7)$ \\
\hline \multirow[t]{3}{*}{6} & Distance & \\
\hline & Near & $200(70.4)$ \\
\hline & Far & $84(29.6)$ \\
\hline \multirow[t]{3}{*}{7} & Travel expense & \\
\hline & Low & $193(68.0)$ \\
\hline & High & $91(32.0)$ \\
\hline \multirow[t]{3}{*}{8} & Adverse effect & \\
\hline & No & $249(87.7)$ \\
\hline & Yes & $35(12.3)$ \\
\hline \multirow[t]{3}{*}{9} & Health education & \\
\hline & No & $101(35.6)$ \\
\hline & Yes & $183(64.4)$ \\
\hline \multirow[t]{3}{*}{10} & Government supply & \\
\hline & Late & $172(60.6)$ \\
\hline & Timely & $112(39.4)$ \\
\hline \multirow[t]{3}{*}{11} & Knowledge & \\
\hline & Low & $170(59.9)$ \\
\hline & High & $114(40.1)$ \\
\hline \multirow[t]{3}{*}{12} & Stigma & \\
\hline & Weak & $254(89.4)$ \\
\hline & Strong & $30(10.6)$ \\
\hline \multirow[t]{3}{*}{13} & Discrimination & \\
\hline & Non-existent & $252(88.7)$ \\
\hline & Existent & $32(11.3)$ \\
\hline \multirow[t]{3}{*}{14} & Family support & \\
\hline & Weak & $46(16.2)$ \\
\hline & Strong & $238(83.8)$ \\
\hline \multirow[t]{3}{*}{15} & Relationship with provider & \\
\hline & Poor & $34(12.0)$ \\
\hline & High & $250(88.0)$ \\
\hline \multirow[t]{3}{*}{16} & $\begin{array}{l}\text { Satisfaction with health } \\
\text { service }\end{array}$ & \\
\hline & Low & $66(23.2)$ \\
\hline & High & $218(76.8)$ \\
\hline \multirow[t]{3}{*}{17} & Trust in health-care provider & \\
\hline & Weak & $26(9.2)$ \\
\hline & Strong & $258(90.8)$ \\
\hline 18 & Depression & \\
\hline & Low & $246(86.6)$ \\
\hline & High & $38(13.4)$ \\
\hline 19 & Adherence to ART & \\
\hline & No & $61(21.5)$ \\
\hline & Yes & $223(78.5)$ \\
\hline
\end{tabular}

IDU: Injecting drug user, ART: Antiretroviral therapy

had a direct positive effect on adherence to HIV treatment, and it was statistically significant. Literally, government supply of ART increased the log odd of adherence to HIV treatment 2.10 units higher than a lack of government supply of ART. Likewise, patient knowledge ( $b=1.70$; $95 \% \mathrm{CI}=0.43$ to $2.95 ; \mathrm{p}=0.008)$ and trust in provider $(\mathrm{b}=2.14 ; 95 \%$ $\mathrm{CI}=-0.58-4.87 ; \mathrm{p}=0.123$ ) had direct positive effects on adherence, and

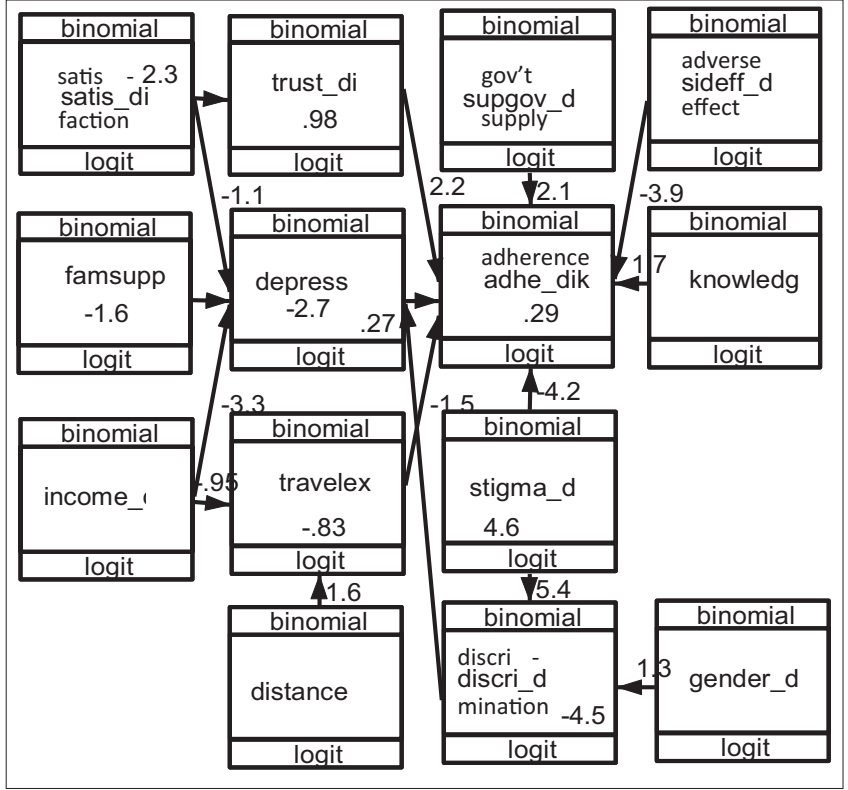

Fig. 1: Path diagram on the determinants of adherence to HIV/ AIDS treatment, based on precede-proceed model

they were statistically significant. For example, high trust in provider increased the log odd of adherence to HIV treatment 2.14 units higher than low trust in provider.

As expected, adverse effect $(b=-4.17 ; 95 \% \mathrm{CI}=-6.87--1.47 ; \mathrm{p}=0.002)$ directly and negatively affected adherence to HIV treatment, and it was statistically significant. Likewise, depression $(\mathrm{b}=-2.38$; $95 \% \mathrm{CI}=-4.15-$ $-0.62 ; \mathrm{p}=0.002)$, stigma ( $\mathrm{b}=-4.10 ; 95 \% \mathrm{CI}=-6.49--1.71 ; \mathrm{p}=0.008)$, and travel expenditure $(b=-1.52 ; 95 \% \mathrm{CI}=-2.68-0.36$; $\mathrm{p}<0.001)$, directly and negatively affected adherence, and they were statistically significant.

Patient satisfaction, income, and family support had indirect positive effects on adherence, whereas discrimination and distance to ART centers had indirect negative effects on adherence.

\section{DISCUSSION}

\section{Adverse effect and adherence}

The current study found that $12.3 \%$ of the sample HIV-infected patients experienced adverse effect (Table 1). Adverse effect was shown to negatively affect adherence to ART. This finding corroborates with previous studies. For example, a meta-analysis conducted by AlDakkak et al. (2013), which combined 18 studies with ART-related adverse effect, reported that adherence to ART was significantly lower in patients with adverse effect than in patients who did not experience adverse effect (odds ratio $=0.62 ; 95 \% \mathrm{CI}=0.47-0.83$ ). The specific AEs identified through this work as having significant negative implications for medication adherence included fatigue, cough, anxiety, confusion, taste disturbances, loss of appetite, and nausea [18].

As Al-Dakkak et al. (2013) added, in the context of combination ART regimens, confusion can be a major barrier to adherence since these regimens entail following detailed and complex recommendations pertaining to the timing, order, and combinations of multiple medications [18].

\section{Depression and adherence}

The present study found that depression negatively affected adherence to HIV treatment. This finding is consistent with a meta-analysis by Di Matteo et al. (2000), which reported that compared with non- 
Table 2: The results of path analysis on adherence to antiretroviral therapy among HIV/AIDS patients

\begin{tabular}{|c|c|c|c|c|c|}
\hline \multirow[t]{2}{*}{ Dependent variable } & \multirow{2}{*}{$\begin{array}{l}\text { Independent } \\
\text { variable }\end{array}$} & \multirow[t]{2}{*}{ Path coefficient } & \multicolumn{2}{|l|}{$95 \% \mathrm{CI}$} & \multirow[t]{2}{*}{$\mathbf{p}$} \\
\hline & & & Lower & Upper & \\
\hline \multicolumn{6}{|l|}{ Direct effect } \\
\hline \multirow{6}{*}{ Adherence } & Travel expenditure & -1.52 & -2.68 & -0.36 & $<0.001$ \\
\hline & Government supply & 2.10 & 0.85 & 3.36 & $<0.001$ \\
\hline & Knowledge & 1.70 & 0.43 & 2.95 & 0.008 \\
\hline & Stigma & -4.10 & -6.49 & -1.71 & 0.008 \\
\hline & Depression & -2.38 & -4.15 & -0.62 & 0.002 \\
\hline & Adverse effect & -4.17 & -6.87 & -1.47 & 0.879 \\
\hline \multicolumn{6}{|l|}{ Indirect effect } \\
\hline \multirow{2}{*}{ Travel expense } & Income & -0.95 & -1.50 & -0.39 & $<0.001$ \\
\hline & Distance & 1.60 & 1.04 & 2.17 & $<0.001$ \\
\hline \multirow[t]{4}{*}{ Depression } & Income & -3.33 & -5.38 & -1.28 & 0.001 \\
\hline & Satisfaction & -1.12 & -2.09 & -0.14 & 0.025 \\
\hline & Discrimination & 4.57 & 2.46 & 6.68 & $<0.001$ \\
\hline & Family Support & -1.62 & -2.59 & -0.64 & 0.001 \\
\hline \multirow[t]{2}{*}{ Discrimination } & Stigma & 5.43 & 4.06 & 6.80 & $<0.001$ \\
\hline & Gender & 1.27 & -0.21 & 2.74 & 0.093 \\
\hline n observation & 284 & & & & \\
\hline Log likelihood & -377.60 & & & & \\
\hline $\mathrm{BIC}$ & 873.83 & & & & \\
\hline AIC & 797.20 & & & & \\
\hline
\end{tabular}

depressed patients, the odds of non-compliant with medical treatment recommendations among depressed patients were 3 times greater [19].

There are three possible underlying mechanisms by which depression might increase non-adherence. First, depression involves some degree of hopelessness and adherence might be difficult for a patient who lacks optimism that any action will be worthwhile. Second, depression is often accompanied by considerable social isolation and withdrawal from the individuals who would be essential in providing emotional support and assistance. Third, depression might be associated with reductions in the cognitive functioning essential to remembering and following through with treatment recommendations (e.g., taking medication) [19].

The result from the current study came from a cross-sectional data, so causal relationship whether depression causes non-adherence or non-adherence causes depression cannot be well established. Causal conclusions would require experimental assessment of a treatment intervention or causal modeling from longitudinal data. However, the authors have attempted an alternative path model with the direction of relationship running from adherence to depression, and the result was statistically non-significant estimate of effect, suggesting the direction of relationship running from depression to adherence seems to be more likely than the reverse direction.

Alternatively, it is possible that a "feedback loop" exists such that depression causes non-adherence to medical treatment and nonadherence further exacerbates depression, with an implication that a clinical focus on both sides might be essential [19].

\section{Stigma and adherence}

Another factor which has been found in the currentstudy to be associated with poor ART adherence is stigmatization. Stigma negatively affected adherence both directly and indirectly through discrimination and depression (Fig. 1). This finding is consistent with previous studies by Joglekar et al., Lyimo et al., and Prasitsuebsai et al. For example, Joglekar et al. (2011) reported that self-perceived stigma was reported to be the reasons for suboptimal adherence to ART in India [20-22].

As an explanation, stigmatization can cause depression, low selfesteem, or psychiatric disorders [22-24], which in turn can lead to nonadherence to treatment and poor health outcomes [22,25].

\section{Trust in provider and adherence}

The current study found that $90.8 \%$ of the sample had high trust in health-care providers (Table 1). Trust in health-care provider was shown to increase adherence. This finding gives clinical implication that trusting relationships between HIV-infected patients and healthcare providers are important to continuity of care. This finding supports the essential role that trust plays in effective doctor-patient relationships. Trust has been shown in previous studies to be a critical factor influencing a variety of important therapeutic processes including patient acceptance of therapeutic recommendations, adherence to recommendations, satisfaction with recommendations, satisfaction with medical care, symptom improvement, and patient disenrollment [26]. For example, a study by Abel and Efird (2013) reported that women with hypertension who trusted their healthcare providers were more likely to be adherent with their prescribed antihypertensive medications than those who did not trust their health-care providers [27].

Mutual trust, therefore, is essential to the patient-heath-care provider relationship and the achievement of positive health outcomes. To enhance trust, it is suggested that health-care providers show competence, caring behaviors, good interpersonal skills, and a desire to promote the health of the patients they serve [27]

\section{Satisfaction, trust, depression, and adherence}

The present study found that $76.8 \%$ of the sample experienced high satisfaction to the health services provided (Table 1). There are two different pathways by which satisfaction indirectly affects adherence. First, patient satisfaction increased trust in health-care provider, which finally increased adherence. Second, patient satisfaction lowered depression, which also finally increased adherence.

The indirect effects of satisfaction were slightly different from a study conducted in the US by Dang et al., which concluded that patient satisfaction had direct effects on retention in HIV care and adherence to HAART [28]. Dang et al. further highlighted the importance of business model of customer satisfaction and retention in the HIV care. They argued that patient satisfaction could serve as an innovative focus for increasing retention in HIV care and adherence to HAART, which in turn serves as key determinants of HIV suppression. Suppression of HIV replication represents the most important prognostic indicator for long-term survival with HIV infection [28]. 
Government supply of ART and adherence

The present study found that good government supply of ART improved its adherence. In Indonesia, the HIV regimens are provided free by the government at the designated public health facilities. During the initial phase of treatment, the HIV-infected patients received ART every 2 weeks. Given patients had no complaints during 2 weeks since the receipt of the first set of pills, the patients receive ART monthly. However, sometimes the patients received ART late leaving some untreated temporarily. About 172 (60.6\%) of patients in this study received ART belatedly (Table 1 ).

\section{Distance, travel expense, and adherence}

The present study found that distance to ART centers and travel expense negatively affected adherence to ART; the farther distance, the larger travel expense, and the poorer adherence. This finding is consistent with a study by Shigdel et al. in Nepal, which reported that travel time to ART centers was independently and negatively associated with ART adherence. Likewise, in the study of Shigdel et al., higher cost of travel to ART center was independently and negatively associated with ART adherence [29].

\section{Income, travel expense, and adherence}

In the present study, income was shown to have a positive indirect effect on adherence through travel expense. Higher income was associated with less travel expense and less travel expense was associated with better adherence. The explanation for this might be that patients with higher income had more options to take the efficient mode to get to the ART center compared with patients with lower income, thereby faced with less travel expense. This finding is consistent with Shigdel et al. in Nepal, which also reported that higher income was associated with better ART adherence [29].

\section{CONCLUSION}

Government supply of ART, patient knowledge, and trust in health-care provider has direct positive effects on adherence to ART. Adverse effect, depression, stigma, and travel expenditure have direct negative effects on adherence to ART. Patient satisfaction, income, and family support have indirect positive effects on adherence to ART. Discrimination and distance to ART centers have indirect negative effects on adherence to ART. All of these determinants can be altered, improved, and capitalized, to develop a better system of care and support for an improved wellbeing of HIV-infected patients.

\section{AUTHOR'S CONTRIBUTION}

Dyah Ayu Agustin raised the original research question, devised questionnaire, collected and analyzed data, drew graph and tables, and edited manuscript. Bhisma Murti designed study and data analysis, wrote up manuscript, discussed the issue and gave suggestion.

\section{CONFLICT OF INTEREST}

The authors certify that they have no affiliations with or involvement in any organization or entity with any financial interest or non-financial interest in the subject matter or materials discussed in this manuscript.

\section{REFERENCES}

1. Mallya SD, Kamath VG, Nair S, Kamath A. Does providing free antiretroviral therapy ensure optimal adherence among people living with human immunodeficiency virus/acquired immunodeficiency syndrome? Asian J Pharm Clin Res 2016;9:1-4.

2. Giordano TP, Suarez-Almazor ME, Grimes RM. The population effectiveness of highly active antiretroviral therapy: Are good drugs good enough? Curr HIV/AIDS Rep 2005;2:177-83.

3. Greenberg AE, Hader SL, Masur H, Young AT, Skillicorn J, Dieffenbach CW. Fighting HIV/AIDS in Washington, D.C. Health Aff 2009;28:1677-87.

4. Gardner EM, McLees MP, Steiner JF, Del Rio C, Burman WJ. The spectrum of engagement in HIV care and its relevance to test-andtreat strategies for prevention of HIV infection. Clin Infect Dis
2011;52:793-800.

5. Rabba AK, Aljiris WS, Ahmed NJ, Alkharfy KM. Medication adherence in Type 2 diabetic patients: A study in Saudi Arabia. Int J Pharm Pharm Sci 2017;9:247-50

6. Max B, Sherer R. Management of the adverse effects of antiretroviral therapy and medication adherence. Clin Infect Dis 2000;30 Suppl 2:S96-116.

7. Masikini P, Mpondo BC. HIV drug resistance mutations following poor adherence in HIV-infected patient: A case report. Clin Case Rep 2015;3:353-6.

8. Shaji J, Shaikh M. Drug-resistant tuberculosis: Recent approach in polymer based nanomedicine. Int J Pharm Pharm Sci 2016;8:1-6.

9. Bangsberg DR, Moss AR, Deeks SG. Paradoxes of adherence and drug resistance to HIV antiretroviral therapy. J Antimicrob Chemother 2004:53:696-9.

10. Centers for Disease Control and Prevention. Monitoring selected national HIV prevention and care objectives using HIV surveillance data-United States and 6 dependent areas, 2014. HIV Surveill Suppl Rep 2016;21. Available from: https://www.cdc.gov/hiv/pdf/ library/reports/surveillance/cdc-hiv-surveillance-supplemental-reportvol-21-4.pdf.

11. Cutler RL, Fernandez-Llimos F, Frommer M, Benrimoj C, GarciaCardenas V. Economic impact of medication non-adherence by disease groups: A systematic review. BMJ Open 2018;8:e016982.

12. Prosperi MC, Fabbiani M, Fanti I, Zaccarelli M, Colafigli M, Mondi A, et al. Predictors of first-line antiretroviral therapy discontinuation due to drug-related adverse events in HIV-infected patients: A retrospective cohort study. BMC Infect Dis 2012;12:296.

13. Green LW, Kreuter MW. CDC's planned approach to community health as an application of PRECEDE and an inspiration for PROCEED. J Health Educ 1992;23:140-7.

14. Crosby R, Noar SM. What is a planning model? An introduction to PRECEDE-PROCEED. J Public Health Dent 2011;71 Suppl 1:S7-15.

15. Harm Research Institute. MINI. Harm Research Institute; 2018. Available from: http://www.harmresearch.org/index.php/miniinternational-neuropsychiatric-interview-mini/\#About $\% 20$ the $\% 20$ MINI. [Last accessed on 2018 Jun].

16. Crow JF. Sewall Wright. 1889-1988. Washington DC: National Academy of Science; 1994.

17. StataCorp LLC. Structural Equation Modeling (SEM). College Station, TX, USA: StataCorp LLC.; 2018.

18. Available from: https://www.stata.com/features/structural-equationmodeling/. [Last accessed on 2018 Jun].

19. Al-Dakkak I, Patel S, McCann E, Gadkari A, Prajapati G, Maiese EM. The impact of specific HIV treatment-related adverse events on adherence to antiretroviral therapy: A systematic review and metaanalysis. AIDS Care 2013;25:400-14.

20. Di Matteo MR, Lepper HS, Croghan TW. Depression is a risk factor for noncompliance with medical treatment. Meta-analysis of the effects of anxiety and depression on patient adherence. Arch Intern Med 2000;160:2101-7.

21. Joglekar N, Paranjape R, Jain R, Rahane G, Potdar R, Reddy KS, et al. Barriers to ART adherence and follow ups among patients attending ART centres in Maharashtra, India. Indian J Med Res 2011;134:954-9.

22. Lyimo RA, Stutterheim SE, Hospers HJ, de Glee T, van der Ven A, de Bruin M, et al. Stigma, disclosure, coping, and medication adherence among people living with HIV/AIDS in northern tanzania. AIDS Patient Care STDS 2014;28:98-105.

23. Prasitsuebsai W, Sethaputra C, Lumbiganon P, Hansudewechakul R, Chokephaibulkit $\mathrm{K}$, Truong $\mathrm{KH}$, et al. Adherence to antiretroviral therapy, stigma and behavioral risk factors in HIV-infected adolescents in asia. AIDS Care 2018;30:727-33.

24. Kingori C, Reece M, Obeng S, Murray M, Shacham E, Dodge B, et al. Impact of internalized stigma on HIV prevention behaviors among HIV-infected individuals seeking HIV care in Kenya. AIDS Patient Care and STDs 2012;26:761-8.

25. White W, Grant JS, Pryor ER, Keltner NL, Vance DE, Raper JL. Do social support, stigma, and social problem-solving skills predict depressive symptoms in people living with HIV? A mediation analysis. Res Theory Nurs Pract 2014;26:182-204. Sweeney SM, Vanable PA. The association of HIV-related stigma to HIV medication adherence: A systematic review and synthesis of the literature. AIDS Behav 2015;20:29-50.

26. Cook KS, Kramer RM, Thom DH, Stepanikova I, Mollborn SB, Cooper RM, et al. Trust and distrust in patient-physician relationships: Perceived determinants of high- and low-trust relationships in managed-care settings. Trust and Distrust in Organizations: Dilemmas 
and Approaches, 2004. New York: Russell Sage Foundation. 2014. p. 65-98.

27. Abel WM, Efird JT. The association between trust in health care providers and medication adherence among black women with hypertension. Front Public Health 2013;1:66.

28. Dang BN, Westbrook RA, Black WC, Rodriguez-Barradas MC,
Giordano TP. Examining the link between patient satisfaction and adherence to HIV care: A structural equation model. PLoS One 2013;8:e54729.

29. Shigdel R, Klouman E, Bhandari A, Ahmed LA. Factors associated with adherence to antiretroviral therapy in HIV-infected patients in Kathmandu District, Nepal. HIV AIDS (Auckl) 2014;6:109-16. 